\title{
Predictive value of calculated plasma osmolality and atherogenic index of plasma for chronic limb-threatening ischemia in lower extremity artery disease
}

\author{
Arda Aybars Pala $\odot$, Yusuf Salim Urcun $\odot$
}

Department of Cardiovascular Surgery, Adiyaman Training and Research Hospital, Adryaman, Turkey

\section{ABSTRACT}

Objectives: Chronic limb-threatening ischemia (CLTI) is the end-stage form of lower extremity artery disease (LEAD) whose main reason is atherosclerosis. Plasma osmolality (PO) and plasma lipid levels affect the development and progression of atherosclerosis directly. The purpose of this study was to investigate the predictive effect of PO and atherogenic index of plasma (AIP) for the development of CLTI.

Methods: A total of 324 patients who were diagnosed with LEAD were analyzed retrospectively. The clinical stage of the disease was evaluated according to the Rutherford classification, and patients without CLTI were defined as "Group 1" and patients with CLTI as "Group 2".

Results: There were 248 patients (mean age $64.44 \pm 9.05$ years and $73.4 \%$ male) in Group 1, and 76 patients (mean age $66.62 \pm 8.22$ years and $76.3 \%$ male) in Group 2. In the multivariate regression analysis, CAD, PO, CRP and AIP were defined as independent predictive factors for the development of CLTI $(p=0.015, p<$ $0.001, p=0.007, p<0.001$; respectively). ROC curve analysis showed that, PO cut-off value for CLTI development was $293.28 \mathrm{mOsm} / \mathrm{kg}$ (AUC: $0.821, p<0.001$ ) with $75 \%$ sensitivity and $74.2 \%$ specificity, and AIP cut-off value was 0.23 (AUC: $0.740, p<0.001$ ) with $67.1 \%$ sensitivity and $68.5 \%$ specificity.

Conclusions: The PO and AIP values in LEAD patients may be used as the new biomarkers of atherosclerosis progression, and therefore as predictive factors for the development of CLTI.

Keywords: Atherogenic index of plasma, chronic limb-threatening ischemia, osmolality, lower extremity artery disease

Paston eripheral artery disease (PAD) is a common disease with its main cause as atherosclerosis. Globally, more than 200 million adults live with PAD. PAD is more common in men and its incidence is increasing, especially in women over the age of 50. The most significant risk factors identified for PAD are diabetes mellitus, hypertension, hyperlipidemia, chronic renal disease and smoking $[1,2]$. Lower extremity artery disease (LEAD) affects the lower extremity arteries and although it is mostly asymptomatic, patients often present with a hospital admission of intermittent claudication. The end-stage form of LEAD associated with high mortality and morbidity is chronic limb-threatening ischemia (CLTI). The diagnosis of CLTI is made clinically, and is characterized by ischemic resting pain, ulcerations and gangrene as a result of arterial blood flow insufficiency due to atherosclerosis progression [3]. 
Plasma osmolality (PO) is associated with the amount of minerals and particles dissolved in the blood. Since it is accepted as an indicator of body hydration, and since it affects endothelial cells, it has been associated with the prognosis of diseases [4, 5]. Fasting blood glucose, sodium $(\mathrm{Na})$ and blood urea nitrogen (BUN) are the main components of PO; and seperate studies were conducted previously on the effects of each one on vascular diseases [6-8]. However, there are no studies in the literature regarding the effect of changes in PO calculated from these components on LEAD.

After understanding the role of plasma lipids in the pathogenesis of atherosclerosis, studies have been conducted to investigate the relationships between lipid profiles and LEAD. Low levels of high-density lipoprotein cholesterol (HDL-C) are among the strongest plasma lipid risk factors for LEAD. There is a relationship between triglyceride (TG) levels and LEAD progression [9]. In the Framingham Offspring Study, increased TG levels and decreased HDL-C levels were associated with increased LEAD risk [10]. In recent years, atherogenic index of plasma (AIP) has been identified as a new predictor of atherosclerosis. AIP is calculated with the logarithmic transformation of TG/HDL-C ratio [11]. Based on this information, we established the hypothesis that AIP could be a powerful biomarker for the development of CLTI.

It is important to know the predictors of CLTI development in patients diagnosed with LEAD, to detect them earlier, and to plan the treatment strategy early for these patients. For this reason, the purpose of this study was to investigate the relation between the development of CLTI and PO values and AIP values to predict the progression of atherosclerosis in patients with LEAD diagnosis, and to contribute to the preventability of atherosclerosis progression with more effective treatment and follow-up.

\section{METHODS}

A total of 324 patients diagnosed with LEAD between January 2018 and June 2020 admitting to our outpatient clinic were included in this study retrospectively, and study approved by local ethics committee (Adiyaman University Clinical Research Ethics Committee, 21.07.2020, 2020/7-3). The patient data were found from the patient files and the hospital registra- tion system.

The LEAD diagnosis in our outpatient clinic is made with clinical examination of patients, ankle brachial systolic pressure index (ABI) measurement and color doppler ultrasonography [12]. Clinical stage evaluation of the disease is done according to the Rutherford classification. In the Rutherford Classification, asymptomatic patients are expressed as "Category 0", mild claudication presence is expressed as "Category 1", moderate claudication presence is expressed as "Category 2", severe claudication presence is expressed as "Category 3", presence of ischemic rest pain is expressed as "Category 4", presence of minor tissue loss presence is expressed as "Category 5", presence of major tissue loss is expressed as "Category 6" [13]. In recent years, "CLTI" definition has been used for category 4 and above in the Rutherford classification [3].

The patients who had a history of surgical or endovascular intervention with a diagnosis of LEAD, patients with acute limb ischemia, patients with diabetes mellitus diagnosis and using antidiabetic drugs, patients with chronic liver or renal disease, patients with known malignancy or systemic inflammatory disease, patients using steroid or statin group drug and patients with familial hyperlipidemia were excluded from the study. After applying these exclusion criteria, patients diagnosed with LEAD and in categories $0,1,2$ and 3 according to the Rutherford classification were included in the study as "Group 1"; and the patients in categories 4, 5 and 6 , that is, those who developed CLTI, were included in the study as "Group 2". The demographic data, comorbidities, and routine blood tests of the patients were evaluated.

\section{Laboratory analysis and calculation of PO and AIP}

The venous blood samples of patients diagnosed with LEAD were evaluated after 12 hours of fasting by taking blood from the antecubital vein into EDTA (ethylenediaminetetraacetic acid) tubes. The automatic analyzer (Abbott CELL-DYN Ruby; Illinois, USA) was used for complete blood count. Fasting blood glucose, creatinine, BUN, Na, HDL-C, TG, low-density lipoprotein cholesterol (LDL-C), total cholesterol (TC) and C-reactive protein (CRP) levels were analyzed with (Abbott 16000; Illinois, USA) automatic analyzer.

The following formula was used to calculate the 
PO: Osmolality $=(\mathrm{BUN} / 2.8)+($ Glucose $/ 18)+(2 \times$ $\mathrm{Na}$ ). And the normal PO value range was described as 275 - $295 \mathrm{mOsm} / \mathrm{kg}$ [14].

The following formula was used to calculate the AIP: AIP $=\log 10$ (TG / HDL-C). In this calculation, concentrations are expressed in $\mathrm{mmol} / \mathrm{L}$ [11].

\section{Statistical Analysis}

The data were analyzed with SPSS 11.5 Program. As descriptive, mean \pm standard deviation and median (minimum-maximum) values were used for quantitative variables, and number of patients (percent) was used for qualitative variables. Shapiro-Wilk test was used to test the normality distribution of the data. In terms of the quantitative variable, the difference between the two categories of qualitative variable categories was checked by Student-t test if the normal distribution assumptions were met; and if not by Mann-Whitney U test. When wanted to examine the relation between qualitative variables, the Chi-Square test was used. The Receiver Operating Characteristic (ROC) analysis was performed to find a method for determining the development of CLTI for the quantitative variable. The cut-off value for the quantitative variable was determined with the Youden Index. The univariate logistic regression and multivariate logistic

Table 1. Comparison of clinical and demographic characteristics of patient groups

\begin{tabular}{|c|c|c|c|c|c|c|c|}
\hline \multirow{2}{*}{\multicolumn{2}{|c|}{ Variables }} & & \multicolumn{2}{|c|}{$\begin{array}{l}\text { Group } 1 \\
(n=248)\end{array}$} & \multicolumn{2}{|c|}{$\begin{array}{c}\text { Group } 2 \\
(n=76)\end{array}$} & \multirow[t]{2}{*}{$p$ value } \\
\hline & & & $\begin{array}{c}\text { Mean } \pm \text { SD } / \\
\text { n (\%) }\end{array}$ & $\begin{array}{c}\text { Median } \\
\text { (Min-Max) }\end{array}$ & $\begin{array}{c}\text { Mean } \pm \text { SD } / \mathbf{n} \\
(\%)\end{array}$ & $\begin{array}{c}\text { Median } \\
\text { (Min-Max) }\end{array}$ & \\
\hline \multicolumn{3}{|c|}{ Age (years) } & $64.44 \pm 9.05$ & $\begin{array}{c}65.00 \\
(44.00-86.00)\end{array}$ & $66.62 \pm 8.22$ & $\begin{array}{c}67.00 \\
(45.00-85.00)\end{array}$ & $0.061^{[\mathrm{a}]}$ \\
\hline Gender & $\begin{array}{l}\text { Male } \\
\text { Female }\end{array}$ & & $\begin{array}{c}182(73.4 \%) \\
66(26.6 \%)\end{array}$ & & $\begin{array}{l}58(76.3 \%) \\
18(23.7 \%)\end{array}$ & & $0.610^{[c]}$ \\
\hline \multicolumn{3}{|c|}{$\mathrm{BMI}\left(\mathrm{kg} / \mathrm{m}^{2}\right)$} & $25.84 \pm 3.47$ & $\begin{array}{c}25.80 \\
(18.60-34.60)\end{array}$ & $26.07 \pm 2.63$ & $\begin{array}{c}26.40 \\
(19.40-33.10)\end{array}$ & $0.542^{[\mathrm{a}]}$ \\
\hline \multicolumn{3}{|c|}{ Hypertension } & $167(67.3 \%)$ & & $54(71.1 \%)$ & & $0.543^{[\mathrm{c}]}$ \\
\hline \multicolumn{3}{|c|}{ CAD } & $106(42.7 \%)$ & & $47(61.8 \%)$ & & $0.004^{[c]}$ \\
\hline \multicolumn{3}{|c|}{ Atrial fibrillation } & $41(16.5 \%)$ & & $13(17.1 \%)$ & & $0.907^{[c]}$ \\
\hline \multicolumn{3}{|c|}{ CVD } & $74(29.8 \%)$ & & $28(36.8 \%)$ & & $0.250^{[\mathrm{cc}]}$ \\
\hline \multicolumn{3}{|c|}{ Current smoking } & $127(51.2 \%)$ & & $43(56.6 \%)$ & & $0.412^{[\mathrm{c}]}$ \\
\hline \multicolumn{3}{|c|}{ COPD } & $55(22.2 \%)$ & & $18(23.7 \%)$ & & $0.783^{[\mathrm{c}]}$ \\
\hline \multicolumn{3}{|l|}{$\mathrm{ABI}$} & $0.59 \pm 0.12$ & $\begin{array}{c}0.57 \\
(0.43-0.89)\end{array}$ & $0.36 \pm 0.07$ & $\begin{array}{c}0.37 \\
(0.19-0.48)\end{array}$ & $<0.001^{[\mathrm{a}]}$ \\
\hline \multicolumn{8}{|c|}{ Rutherford category } \\
\hline \multirow{7}{*}{\multicolumn{2}{|c|}{ 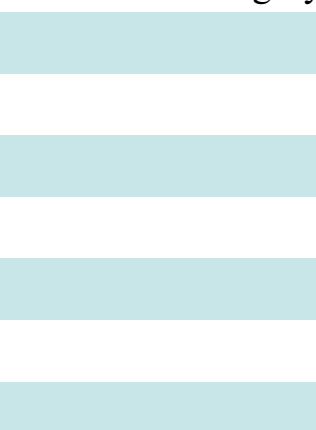 }} & 0 & $23(9.3 \%)$ & & 0 & & $<0.001^{[\mathrm{c}]}$ \\
\hline & & 1 & $73(29.4 \%)$ & & 0 & & \\
\hline & & 2 & $89(35.9 \%)$ & & 0 & & \\
\hline & & 3 & $63(25.4 \%)$ & & 0 & & \\
\hline & & 4 & 0 & & $37(48.7 \%)$ & & \\
\hline & & 5 & 0 & & $28(36.8 \%)$ & & \\
\hline & & 6 & 0 & & $11(14.5 \%)$ & & \\
\hline
\end{tabular}

$\mathrm{SD}=$ Standard deviation, Min = Minimum, Max =Maximum; ${ }^{[\mathrm{a}]}$ Student-t test, ${ }^{[\mathrm{c}]}$ Chi-square test, BMI = Body mass index, $\mathrm{CAD}=$ Coronary artery disease, $\mathrm{CVD}=$ Cerebrovascular disease, $\mathrm{COPD}=$ Chronic obstructive pulmonary disease, $\mathrm{ABI}=$ Ankle brachial index 
Table 2. Comparison of laboratory variables of patient groups

\begin{tabular}{|c|c|c|c|c|c|}
\hline \multirow[t]{2}{*}{ Variables } & \multicolumn{2}{|c|}{$\begin{array}{l}\text { Group } 1 \\
(n=248)\end{array}$} & \multicolumn{2}{|c|}{$\begin{array}{l}\text { Group } 2 \\
(n=76)\end{array}$} & \multirow[t]{2}{*}{$p$ value } \\
\hline & $\begin{array}{c}\text { Mean } \pm \text { SD / } \\
\text { n (\%) }\end{array}$ & $\begin{array}{c}\text { Median } \\
\text { (Min-Max) }\end{array}$ & $\begin{array}{c}\text { Mean } \pm \text { SD / } \\
\text { n (\%) }\end{array}$ & $\begin{array}{c}\text { Median } \\
\text { (Min-Max) }\end{array}$ & \\
\hline $\begin{array}{l}\text { Fasting blood glucose } \\
(\mathrm{mg} / \mathrm{dL})\end{array}$ & $112.68 \pm 23.95$ & $\begin{array}{c}112.00 \\
(65.00-193.00)\end{array}$ & $121.97 \pm 24.30$ & $\begin{array}{c}120.00 \\
(74.00-182.00)\end{array}$ & $0.003^{[\mathrm{a}]}$ \\
\hline Creatinine (mg/dL) & $0.91 \pm 0.30$ & $\begin{array}{c}0.86 \\
(0.50-2.38)\end{array}$ & $0.90 \pm 0.21$ & $\begin{array}{c}0.93 \\
(0.70-2.21)\end{array}$ & $0.423^{[b]}$ \\
\hline $\begin{array}{l}\text { Blood urea nitrogen } \\
(\mathrm{mg} / \mathrm{dL})\end{array}$ & $20.96 \pm 5.35$ & $\begin{array}{c}20.00 \\
(11.00-37.00)\end{array}$ & $24.79 \pm 6.94$ & $\begin{array}{c}24.50 \\
(14.00-42.00)\end{array}$ & $<0.001^{[\mathrm{a}]}$ \\
\hline $\begin{array}{l}\text { Sodium } \\
(\mathrm{mEq} / \mathrm{L})\end{array}$ & $137.31 \pm 3.22$ & $\begin{array}{c}137.00 \\
(129.00-147.00)\end{array}$ & $140.91 \pm 2.92$ & $\begin{array}{c}141.00 \\
(133.00-145.00)\end{array}$ & $<0.001^{[\mathrm{a}]}$ \\
\hline $\mathrm{PO}(\mathrm{mOsm} / \mathrm{kg})$ & $288.36 \pm 7.22$ & $\begin{array}{c}287.36 \\
(272.38-312.54)\end{array}$ & $297.45 \pm 6.78$ & $\begin{array}{c}297.32 \\
(280.37-311.94)\end{array}$ & $<0.001^{[\mathrm{a}]}$ \\
\hline $\mathrm{TC}(\mathrm{mmol} / \mathrm{L})$ & $5.19 \pm 0.61$ & $\begin{array}{c}5.28 \\
(3.58-6.50)\end{array}$ & $5.16 \pm 0.67$ & $\begin{array}{c}5.26 \\
(3.65-6.72)\end{array}$ & $0.694^{[\mathrm{a}]}$ \\
\hline $\mathrm{TG}(\mathrm{mmol} / \mathrm{L})$ & $1.66 \pm 0.41$ & $\begin{array}{c}1.67 \\
(0.78-2.89)\end{array}$ & $1.83 \pm 0.42$ & $\begin{array}{c}1.85 \\
(0.91-2.81)\end{array}$ & $0.002^{[\mathrm{a}]}$ \\
\hline HDL-C (mmol/L) & $1.13 \pm 0.16$ & $\begin{array}{c}1.16 \\
(0.80-1.45)\end{array}$ & $0.96 \pm 0.10$ & $\begin{array}{c}0.93 \\
(0.80-1.19)\end{array}$ & $<0.001^{[\mathrm{a}]}$ \\
\hline LDL-C (mmol/L) & $3.29 \pm 0.55$ & $\begin{array}{c}3.41 \\
(2.02-4.40)\end{array}$ & $3.36 \pm 0.58$ & $\begin{array}{c}3.48 \\
(2.04-4.73)\end{array}$ & $0.372^{[\mathrm{a}]}$ \\
\hline AIP & $0.16 \pm 0.14$ & $\begin{array}{c}0.17 \\
(-0.26-0.55)\end{array}$ & $0.27 \pm 0.11$ & $\begin{array}{c}0.28 \\
(-0.02-0.54)\end{array}$ & $<0.001^{[b]}$ \\
\hline $\begin{array}{l}\text { C-reactive protein } \\
(\mathrm{mg} / \mathrm{dL})\end{array}$ & $4.77 \pm 2.95$ & $\begin{array}{c}3.56 \\
(0.70-13.70)\end{array}$ & $5.84 \pm 3.18$ & $\begin{array}{c}5.01 \\
(1.02-12.80)\end{array}$ & $0.005^{[b]}$ \\
\hline Hemoglobin (g/dL) & $13.34 \pm 1.77$ & $\begin{array}{c}13.50 \\
(9.20-16.90)\end{array}$ & $12.95 \pm 1.80$ & $\begin{array}{c}12.75 \\
(9.80-17.40)\end{array}$ & $0.094^{[\mathrm{a}]}$ \\
\hline $\begin{array}{l}\text { White blood cell } \\
(103 / \mu \mathrm{L})\end{array}$ & $8.57 \pm 2.26$ & $\begin{array}{c}8.42 \\
(4.89-14.12)\end{array}$ & $8.84 \pm 2.19$ & $\begin{array}{c}8.57 \\
(5.14-14.85)\end{array}$ & $0.361^{[\mathrm{a}]}$ \\
\hline Platelet $(103 / \mu \mathrm{L})$ & $247.01 \pm 64.69$ & $\begin{array}{c}238.50 \\
(104.00-496.00)\end{array}$ & $237.34 \pm 67.85$ & $\begin{array}{c}224.00 \\
(129.00-479.00)\end{array}$ & $0.149^{[b]}$ \\
\hline $\begin{array}{l}\text { Mean platelet volume } \\
\text { (fL) }\end{array}$ & $8.83 \pm 1.18$ & $\begin{array}{c}8.77 \\
(6.45-11.24) \\
\end{array}$ & $9.27 \pm 1.30$ & $\begin{array}{c}9.53 \\
(6.26-11.35)\end{array}$ & $0.006^{[\mathrm{a}]}$ \\
\hline
\end{tabular}

$\mathrm{SD}=$ Standard deviation, Min = Minimum, Max =Maximum; [a]Student-t test, [b]Mann-Whitney U test, PO = Plasma osmolality, $\mathrm{TC}=$ Total cholesterol, $\mathrm{TG}=$ Triglyceride, HDL-C $=$ High-density lipoprotein cholesterol, LDL-C $=$ Lowdensity lipoprotein cholesterol, AIP = Atherogenic index of plasma 
regression analyzes were performed to show risk factors for CLTI development. Statistical significance level was accepted as $p<0.05$.

\section{RESULTS}

This study included 324 patients diagnosed with LEAD. There were 248 patients in Group 1 (mean age $64.44 \pm 9.05$ years; $73.4 \%$ male) and 76 patients in Group 2 (mean age $66.62 \pm 8.22$ years; $76.3 \%$ male). The mean ABI measurement of patients in Group 1 was $0.59 \pm 0.11$; and that of patients in Group 2 was $0.36 \pm 0.08(p<0.001)$. No significant difference was found between the patient groups in terms of gender, age, body mass index, hypertension, atrial fibrillation, cerebrovascular disease, current smoking status, and chronic obstructive pulmonary disease. Patients in Group 2 had significantly higher concomitant coronary artery disease (CAD) compared to Group 1 $(61.8 \%$ vs $42.7 \%, p=0.004)$. The clinical and demographic characteristics of the patient groups are shown in Table 1.

When the laboratory variables of patient groups were compared, it was found that the values of $\mathrm{Na}$, BUN, fasting blood glucose and PO were significantly higher in Group $2(p<0.001, p<0.001, p=0.003, p$ $<0.001$; respectively). HDL-C value, which is one of the lipid profile variables, was significantly lower in
Group 2, while TG and AIP values were found to be high ( $p<0.001, p=0.002, p<0.001$; respectively). $\mathrm{CRP}$ and mean platelet volume (MPV) values were also found to be significantly higher in Group $2(p=$ $0.005, p=0.006$; respectively) (Table 2).

When the results of univariate logistic regression analysis that was done to determine possible predictors of the development of CLTI were evaluated, CAD, PO, AIP, MPV and CRP variables were found to be significant risk factors, and these variables were included in the multivariate analysis (Table 3 ). And according to this analysis, CAD, PO, CRP and AIP variables were found to be independent predictive factors for the development of CLTI $(p=0.015, p<$ $0.001, p=0.007, p<0.001$; respectively).

To determine the predictive effect of PO and AIP levels in the development of CLTI, ROC Curve analysis was done. The ideal cut-off value for calculated PO was $293.28 \mathrm{mOsm} / \mathrm{kg}$ (Area Under the Curve [AUC]: $0.821, p<0.001)$ with $75 \%$ sensitivity and $74.2 \%$ specificity. The ideal cut-off value for AIP was 0.23 (AUC: $0.740, p<0.001$ ) with $67.1 \%$ sensitivity and $68.5 \%$ specificity (Fig. 1 ).

\section{DISCUSSION}

The relation between CLTI development and calculated PO values and AIP values was investigated in

Table 3. Univariate and multivariate logistic regression analysis to determine predictors of the development of chronic limb-threatening ischemia

\begin{tabular}{lcccccc}
\hline Variables & \multicolumn{3}{c}{ Univariate analysis } & \multicolumn{2}{c}{ Multivariate analysis } \\
& $\boldsymbol{p}$ value & OR & $\begin{array}{c}\mathbf{9 5 \%} \text { CI } \\
\text { Lower-Upper }\end{array}$ & $\boldsymbol{p}$ value & OR & $\begin{array}{c}\text { 95\% CI } \\
\text { Lower-Upper }\end{array}$ \\
\hline Age & 0.062 & 1.028 & $0.999-1.059$ & & & \\
Gender (Male) & 0.610 & 1.168 & $0.642-2.127$ & & & \\
CAD & $\mathbf{0 . 0 0 4}$ & 2.171 & $1.282-3.677$ & $\mathbf{0 . 0 1 5}$ & 2.245 & $1.171-4.304$ \\
Smoking & 0.413 & 1.241 & $0.740-2.083$ & & & \\
PO & $<\mathbf{0 . 0 0 1}$ & 1.182 & $1.131-1.236$ & $<\mathbf{0 . 0 0 1}$ & 1.168 & $1.114-1.225$ \\
AIP & $<\mathbf{0 . 0 0 1}$ & 1406.004 & $120.477-16408.483$ & $<\mathbf{0 . 0 0 1}$ & 735.730 & $41.043-1188.634$ \\
CRP & $\mathbf{0 . 0 0 8}$ & 1.115 & $1.028-1.208$ & $\mathbf{0 . 0 0 7}$ & 1.156 & $1.040-1.285$ \\
MPV & $\mathbf{0 . 0 0 7}$ & 1.352 & $1.087-1.680$ & & & \\
\hline
\end{tabular}

$\mathrm{OR}=$ Odds ratio, $\mathrm{CI}=$ Confidence interval, $\mathrm{CAD}=$ Coronary artery disease, $\mathrm{PO}=$ Plasma osmolality, $\mathrm{AIP}=$ Atherogenic index of plasma, $\mathrm{CRP}=\mathrm{C}$-Reactive protein, $\mathrm{MPV}=$ Mean platelet volume 


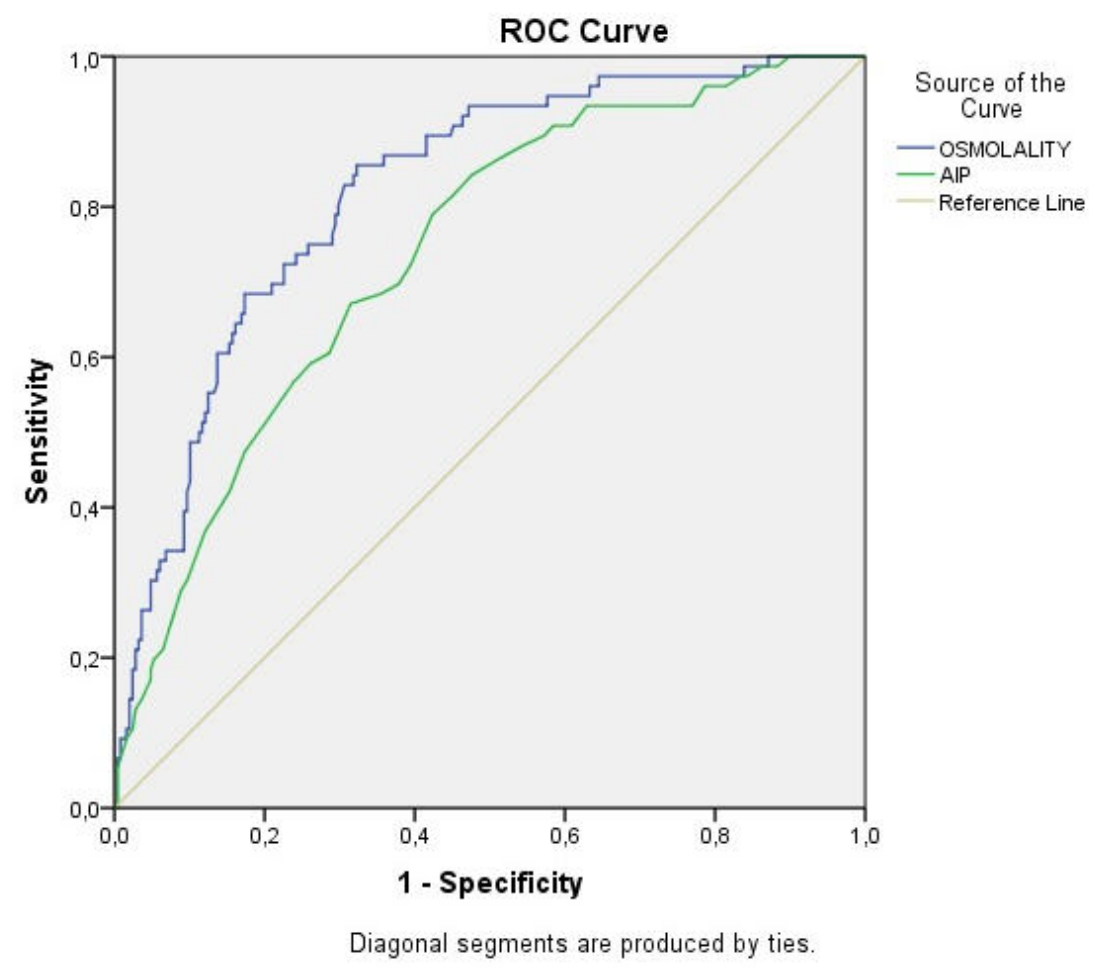

Fig. 1. ROC curve of calculated PO and AIP for predicting the development of chronic limb-threatening ischemia.

this retrospective study. We found that the increase in PO values and AIP values was related with the development of CLTI in patients with LEAD. In the multivariate logistic regression analysis, $\mathrm{CAD}, \mathrm{CRP}, \mathrm{PO}$ and AIP variables were found as independent predictive factors for CLTI development. In patients with LEAD diagnosis, it was found that having concomitant CAD increased the risk of developing CLTI by 2.245 times, one unit increase in CRP quantitative variable increased the risk of developing CLTI by 1.156 times, one unit increase of PO quantitative variable increased the risk of developing CLTI by 1.168 times, and 0.1 unit increase in AIP quantitative variable increased the risk of developing CLTI by 1.935 times. To the best of our knowledge, we determined for the first time in the literature with this study that the development of CLTI can be predicted with PO values and AIP values in patients with LEAD diagnosis.

CLTI is the end-stage of LEAD, and is related with high morbidity and mortality. It was reported that, major amputation rate was 30\% and mortality rate was $25 \%$ in patients within 1 year after the development of CLTI [15]. Therefore, it is important to plan the treatment of LEAD patients before CLTI develops. In addition to medical treatments (antithrombotic, lipid- lowering, antihypertensive agents) and treatment approaches such as exercise, diet, smoking cessation, and preventive foot care applied in symptomatic LEAD patients, early revascularization options are also recommended for patients at high risk of developing CLTI $[1,3]$. In recent years, many predictors of CLTI development have been identified in patients diagnosed with LEAD $[16,17]$. Since atherosclerosis is the underlying cause of LEAD pathology, the identified predictors are focused on atherosclerosis, which is considered an inflammatory process.

Atherosclerosis is multifactorial and inflammation plays an important role in its patagonesis from its development to its progression. Plasma osmolality can be defined as the solite load in the body, and indicates body hydration. The increase in PO increases the inflammation and atherosclerosis progression in vascular endothelial cells by increasing the hemoconcentration $[18,19]$. In their study of 315 patients, Rasouli et al. [4] reported that calculated PO, which is one of the markers of dehydration and hemoconcentration, showed correlations with CAD severity. In a study on 3748 acute coronary syndrome patients conducted by Tatlisu et al. [20], it was reported that PO at admission could be used to identify high-risk patients and is a predictor of in-hospital and long-term 
mortality. Similar to these studies in the literature, statistically significant high $\mathrm{PO}$ values were found in patients who developed CLTI in our study $(p<0.001)$. In addition, $\mathrm{PO}$ has been found to be an independent predictor of CLTI development (odds ratio (OR): $1.168,95 \%$ confidence interval $(\mathrm{CI}): 1.114-1.225, p<$ $0.001)$. It is known that diabetes mellitus is an important risk factor in LEAD etiology, increasing the risk of LEAD development by three-four times. It also accelerates the development of CLTI by increasing vascular inflammation and delaying the diagnosis and treatment of the disease with peripheral neuropathy effect [15]. In addition, since diabetes mellitus would increase PO alone, and reduce the reliability of the results of our study; patients with diabetes mellitus diagnosis and using antidiabetic drugs were not included in the study. Also, patients with chronic renal disease, which has close relations with atherosclerosis progression, and which might change PO with direct effect on plasma electrolyte values, were also excluded from the study [21].

Dyslipidemia causes the development and progression of atherosclerosis by affecting vascular endothelial cells. High TC and LDL-C levels are considered to be risk factors for LEAD, and low HDL$\mathrm{C}$ levels were significantly associated with increased mortality and other cardiovascular complications in LEAD patients $[22,23]$. Small dense LDL-C is the subfraction of LDL-C with high atherogenic potential, and increases in direct proportion with TG levels. For this reason, there is a strong relation between the increase in TG levels and atherosclerotic diseases [24]. Recently, AIP, which is calculated with the logarithmic transformation of plasma TG and HDL-C molar levels, has been described as a novel and powerful clinical biomarker for atherosclerotic diseases [11, 25]. In their prospective studies in which 2676 middle-aged individuals were included with a follow-up period of 7.8 years, Onat et al. [26] reported that AIP variable was an independent predictive factor for CAD. In the case-control study of 696 individuals conducted by Wu et al. [27], AIP was reported to be a strong predictive biomarker for CAD risk in women (OR: 3.290, 95\% CI: $1.842-5.877, p<0.001)$. In a meta-analysis summarizing the data related to AIP calculated in 8394 individuals, it was reported that the values -0.3 to 0.1 were associated with low, 0.1 to 0.24 were associated with medium and above 0.24 were associated with high cardiovascular disease risk [28]. In our study, which included patients with LEAD diagnosis, statistically significant high AIP values were detected in patient group with CLTI, and AIP was detected as an independent predictive factor for CLTI development. The ideal AIP cut-off value for CLTI development was found as 0.23 with $67.1 \%$ sensitivity and $68.5 \%$ specificity.

In our study, statistically significant low HDL-C levels and high CRP levels were noted in patient group with CLTI $(p<0.001, p=0.005$; respectively). HDL$\mathrm{C}$ is known as antiatherogenic lipoprotein due to its reverse cholesterol transport properties. Additionally, it has antioxidant and anti-inflammatory properties, and in particular, it inhibits vascular inflammation by inhibiting the expression of adhesion molecules from endothelial cells. For this reason, there is a negative correlation between HDL-C and CRP, which are inflammatory biomarkers [23]. It was also shown that there is a relation between elevation in CRP levels and the severity of atherosclerosis and LEAD [1]. Swastini et al. [29] investigated the relationship between CRP and atherosclerosis severity measured by ABI and doppler ultrasonography in 388 patients with dyslipidemia. They published that there was a important correlation between CRP levels and the severity of atherosclerosis. Barani et al. [30] associated CRP levels with 1-year mortality in CLTI patients. Based on our findings, we found that the CRP level is an independent predictive factor for CLTI development (OR: 1.156, 95\% CI: $1.040-1.285, p=0.007)$.

Atherosclerosis is a systemic disease, affecting many arteries simultaneously. Patients with LEAD diagnosis have concomitant CAD at a rate between $40 \%$ and $55 \%[15,31]$. It has been reported that the presence of CAD is an independent risk factor for mortality [32]. A total of $47.2 \%$ of the patients who were included in our study had concomitant CAD, and there were significantly higher CAD in patient group with CLTI. It was found that concomitant CAD in LEAD patients is an independent predictive factor for CLTI development (OR: 2.245, 95\% CI: 1.171-4.304, $p=$ $0.015)$.

\section{Limitations}

Our study had several limitations to consider. First of all, our study was single-centered, and was designed retrospectively. Patients who were diagnosed with 
LEAD, that is, mostly symptomatic, with outpatient clinic application were included in our study. The rate of presence of symptoms in LEAD patients is 35\% [33]. For this reason, studies that involve wider patient populations, including asymptomatic LEAD patients, should be planned to ensure that these two laboratory parameters we calculated to enter clinical use. In addition, stating the smoking status as only current smokers, not as pack years or former smokers, can be considered as another limitation of our study.

\section{CONCLUSION}

According to the data of our study, it was found that PO values and AIP values that are calculated simply from routine biochemical tests in patients with LEAD diagnosis were associated with the development of CLTI. Our analysis showed that CAD, PO, AIP and CRP are independent predictive factors for for CLTI development in patients with LEAD diagnosis. Since these patients may benefit from aggressive management of risk factors and intensified treatment options to prevent CLTI-related morbidity and mortality, we believe that identifying the high-risk population for the development of CLTI in patients with a diagnosis of LEAD is of great importance.

\section{Authors' Contribution}

Study Conception: AAP; Study Design: AAP, YSU; Supervision: AAP; Funding: AAP; Materials: AAP; Data Collection and/or Processing: AAP, YSU; Statistical Analysis and/or Data Interpretation: AAP, YSU; Literature Review: AAP; Manuscript Preparation: AAP and Critical Review: AAP, YSU.

\section{Conflict of interest}

The authors disclosed no conflict of interest during the preparation or publication of this manuscript.

\section{Financing}

The authors disclosed that they did not receive any grant during the conduction or writing of this study.

\section{REFERENCES}

1. Conte MS, Bradbury AW, Kolh P, White JV, Dick F, Fitridge
$\mathrm{R}$, et al. Global vascular guidelines on the management of chronic limb-threatening ischemia. J Vasc Surg. 2019;69(6S):3S125S.e40. Erratum in: J Vasc Surg 2019;70:662.

2. Yavuz Ş, Özsin KK, Sanrı US, Toktaş F. Peripheral artery disease in women. Eur Res J 2020;6:178-86.

3. Aboyans V, Ricco JB, Bartelink MEL, Björck M, Brodmann M, Cohnert T, et al. 2017 ESC Guidelines on the Diagnosis and Treatment of Peripheral Arterial Diseases, in collaboration with the European Society for Vascular Surgery (ESVS): Document covering atherosclerotic disease of extracranial carotid and vertebral, mesenteric, renal, upper and lower extremity arteries. Eur Heart J 2018;39:763-816.

4. Rasouli M, Kiasari AM, Arab S. Indicators of dehydration and haemoconcentration are associated with the prevalence and severity of coronary artery disease. Clin Exp Pharmacol Physiol 2008;35:889-94.

5. Kanat S, Demirci H, Üstündağ Y, Can FE, Aydın U, Ocakoğlu G. Effect of serum osmolality on 6-year survival rates in patients with acute myocardial infarction. Turk J Clin Lab 2020;1:24-32. 6. Beckman JA, Paneni F, Cosentino F, Creager MA. Diabetes and vascular disease: pathophysiology, clinical consequences, and medical therapy: part II. Eur Heart J 2013;34:2444-52.

7. Bae MH, Kim JH, Jang SY, Park SH, Lee JH, Yang DH, et al. Hyponatremia at discharge as a predictor of 12-month clinical outcomes in hospital survivors after acute myocardial infarction. Heart Vessels 2017;32:126-133.

8. Gary T, Pichler M, Schilcher G, Hafner F, Hackl G, Rief P, et al. Elevated blood urea nitrogen is associated with critical limb ischemia in peripheral arterial disease patients. Medicine (Baltimore) 2015;94:e948.

9. Aday AW, Everett BM. Dyslipidemia profiles in patients with peripheral artery disease. Curr Cardiol Rep 2019;21:42.

10. Murabito JM, Evans JC, Nieto K, Larson MG, Levy D, Wilson PW. Prevalence and clinical correlates of peripheral arterial disease in the Framingham Offspring Study. Am Heart J 2002;143:961-5.

11. Shen S, Lu Y, Qi H, Li F, Shen Z, Wu L, et al. Association between ideal cardiovascular health and the atherogenic index of plasma. Medicine (Baltimore) 2016;95:e3866. Erratum in: Medicine (Baltimore) 2016;95:e5074.

12. Crawford F, Welch K, Andras A, Chappell FM. Ankle brachial index for the diagnosis of lower limb peripheral arterial disease. Cochrane Database Syst Rev 2016;9:CD010680.

13. Rutherford RB, Baker JD, Ernst C, Johnston KW, Porter JM, Ahn S, et al. Recommended standards for reports dealing with lower extremity ischemia: revised version. J Vasc Surg 1997;26:517-38. Erratum in: J Vasc Surg 2001;33:805.

14. Fazekas AS, Funk GC, Klobassa DS, Rüther H, Ziegler I, Zander R, et al. Evaluation of 36 formulas for calculating plasma osmolality. Intens Care Med 2013;39:302-8.

15. Norgren L, Hiatt WR, Dormandy JA, Nehler MR, Harris KA, Fowkes FG, et al. Inter-Society Consensus for the Management of Peripheral Arterial Disease (TASC II). J Vasc Surg 2007;45 Suppl S:S5-67.

16. Guetl K, Raggam RB, Muster V, Gressenberger P, Vujic J, Avian A, et al. The white blood cell count to mean platelet volume ratio for the prediction of chronic limb-threatening ischemia 
in lower extremity artery disease. J Clin Med 2019;8:1593.

17. Teperman J, Carruthers D, Guo Y, Barnett MP, Harris AA, Sedlis SP, et al. Relationship between neutrophil-lymphocyte ratio and severity of lower extremity peripheral artery disease. Int J Cardiol 2017;228:201-4.

18. Mathur RK. The role of hyperosmolal food in the development of atherosclerosis. Med Hypotheses 2005;64:579-81.

19. Moriya J. Critical roles of inflammation in atherosclerosis. J Cardiol. 2019;73:22-7.

20. Tatlisu MA, Kaya A, Keskin M, Uzman O, Borklu EB, Cinier $\mathrm{G}$, et al. Can we use plasma hyperosmolality as a predictor of mortality for ST-segment elevation myocardial infarction? Coron Artery Dis 2017;28:70-6.

21. Valdivielso JM, Rodríguez-Puyol D, Pascual J, Barrios C, Bermúdez-López M, Sánchez-Niño MD, et al. Atherosclerosis in chronic kidney disease: more, less, or just different? Arterioscler Thromb Vasc Biol 2019;39:1938-66.

22. Martinez-Aguilar E, Orbe J, Fernández-Montero A, Fernández-Alonso S, Rodríguez JA, Fernández-Alonso L, et al. Reduced high-density lipoprotein cholesterol: A valuable, independent prognostic marker in peripheral arterial disease. J Vasc Surg 2017;66:1527-33.e1.

23. Barter PJ, Nicholls S, Rye KA, Anantharamaiah GM, Navab M, Fogelman AM. Antiinflammatory properties of HDL. Circ Res 2004;95:764-72.

24. Peng J, Luo F, Ruan G, Peng R, Li X. Hypertriglyceridemia and atherosclerosis. Lipids Health Dis 2017;16:233.

25. Sayın S, Kutlu R, Koçak A. The relationship between atherogenic index of plasma and major risk factors of cardiovascular disease in obese and nonobese individuals. Eur Res J 2019;5:678-
85.

26. Onat A, Can G, Kaya H, Hergenç G. "Atherogenic index of plasma" (log10 triglyceride/high-density lipoprotein-cholesterol) predicts high blood pressure, diabetes, and vascular events. J Clin Lipidol 2010;4:89-98.

27. Wu TT, Gao Y, Zheng YY, Ma YT, Xie X. Atherogenic index of plasma (AIP): a novel predictive indicator for the coronary artery disease in postmenopausal women. Lipids Health Dis 2018; 17:197.

28. Dobiásová M. [AIP--atherogenic index of plasma as a significant predictor of cardiovascular risk: from research to practice]. Vnitr Lek 2006;52:64-71. [Article in Czech]

29. Swastini DA, Wiryanthini IAD, Ariastuti NLP, Muliantara A. Atherosclerosis prediction with high sensitivity C-reactive protein (hs-CRP) and related risk factor in patient with dyslipidemia. Open Access Maced J Med Sci 2019; 7:3887-90.

30. Barani J, Nilsson JA, Mattiasson I, Lindblad B, Gottsäter A. Inflammatory mediators are associated with 1-year mortality in critical limb ischemia. J Vasc Surg 2005;42:75-80.

31. Hur DJ, Kizilgul M, Aung WW, Roussillon KC, Keeley EC. Frequency of coronary artery disease in patients undergoing peripheral artery disease surgery. Am J Cardiol 2012;110:736-40. 32. Chen DC, Singh GD, Armstrong EJ, Waldo SW, Laird JR, Amsterdam EA. Long-term comparative outcomes of patients with peripheral artery disease with and without concomitant coronary artery disease. Am J Cardiol 2017;119:1146-52.

33. Sigvant B, Lundin F, Wahlberg E. The risk of disease progression in peripheral arterial disease is higher than expected: a meta-analysis of mortality and disease progression in peripheral arterial disease. Eur J Vasc Endovasc Surg 2016;51:395-403. 